\title{
Shear behaviour of laminated neoprene bridge bearing pads under thermal aging condition
}

\author{
Xie Jun ${ }^{\mathrm{a}}$, Yannian Zhang ${ }^{\mathrm{a}, \mathrm{b} *}$, Chunhong Shan ${ }^{\mathrm{b}}$ \\ (a. Hebei Key Laboratory for Diagnosis, Reconstruction and Anti-disaster of Civil Engineering, \\ Zhangjiakou,075000, China ; \\ b. School of Civil Engineering, Shenyang Jianzhu University, Shenyang, 110168, China)
}

\begin{abstract}
Keywords: bridge bearing pads; thermal aging; shear tests; shear capacity
Abstract: The present study was conducted to obtain a better understanding of the variation rule of mechanical properties of laminated neoprene bridge bearing pads under thermal aging condition using shear tests. A total of 5 specimens were processed in a high-temperature chamber. After that, the specimens were tested subjected to horizontal load. The results of shear tests show that the specimens after thermal aging processing are more probably brittle failure than the standard specimen. Moreover, the exposure of steel plate, cracks and other failure phenomena are more serious than the standard specimen. The attenuation trends of ultimate shear strength, shear elastic modulus of laminated neoprene bridge bearing pads under thermal aging condition accord with power function. The attenuation models conform to reality well which shows that this model is applicable and has vast prospect in assessing the performance of laminated neoprene bridge bearing pads under thermal aging condition.
\end{abstract}

\section{Introduction}

Neoprene has good aging property [1 3], but its physics-mechanical properties deteriorate under thermal aging condition [4]. There is an already vast amount of research into the effects of heating on the behavior of laminated rubber bearings [5 9]. However, there is a lack of the effects of heating on the behavior of laminated neoprene bridge bearing pads. The impact of climate is more serious to highway bridge rubber bearings than building rubber bearings. The deterioration of mechanical properties of laminated neoprene bridge bearing pads in line with rising aging time is a serious concern, but there is a lack of experimental data on the relationship between increased aging time and its mechanical properties. To confirm the effects of longer aging time caused by thermal aging condition on the mechanical properties of laminated neoprene bridge bearing pads, Shear tests were carried out after specimens processed in high-temperature test chamber for different lengths of time.

\section{Experimental Program}

\subsection{Test specimens}

Table 1 Specification of test specimens

\begin{tabular}{|c|c|c|c|c|c|c|c|c|c|}
\hline specimens & $\mathrm{Ls} / \mathrm{mm}$ & $\mathrm{LL}_{\mathrm{L}} \mathrm{mm}$ & $\mathrm{T} / \mathrm{mm}$ & S & $\Delta l_{1} / \mathrm{mm}$ & $\Delta l_{2} / \mathrm{mm}$ & $\mathrm{t}_{\mathrm{e}} / \mathrm{mm}$ & $\mathrm{t}_{1} / \mathrm{mm}$ & $\mathrm{t}_{0} / \mathrm{mm}$ \\
\hline GJZ200×300×41(CR) & 200 & 300 & 41 & 7.17 & 12.0 & 16.8 & 29 & 8 & 3 \\
\hline
\end{tabular}

The specimens are denoted by GJZLs $\times$ LL $\times \mathrm{T}(\mathrm{CR})$ [10], where GJZ indicates rectangular bridge bearing pads; Ls is the length of short edges of rectangular bridge bearing pads; $L_{L}$ is the length of long edges of rectangular bridge bearing pads; $T$ is the thickness of rectangular bridge bearing pads; $\mathrm{CR}$ indicates bearing pads are made of neoprene; $\mathrm{S}$ is the primary shape factor of rectangular bridge bearing pads; $\Delta l_{1}$ is maximal displacement value regardless of brake force; $\Delta l_{2}$ is maximal displacement value considering of brake force; te is the total thickness of neoprene layers; $t_{1}$ is the thickness of a neoprene layer; $t_{0}$ is the thickness of a steel plate layer. The specification of test specimens in detail is described in Table 1.

\subsection{Material Properties}

All test specimens were made in Chinese Hengshui Xinli Engineering Inc, and the physical and 
mechanical properties of specimens in detail are described in Table 2.

Table 2 Physical and mechanical properties of specimens

\begin{tabular}{|c|c|c|c|c|c|c|c|}
\hline specimens & $\begin{array}{c}\text { hardness } \\
\text { (IRHD) }\end{array}$ & $\begin{array}{c}\text { tensile } \\
\text { strength } \\
(\mathrm{MPa})\end{array}$ & $\begin{array}{l}\text { elongation } \\
\text { at } \\
\text { rupture }(\%)\end{array}$ & $\begin{array}{l}\text { peeling } \\
\text { strength } \\
(\mathrm{kN} / \mathrm{m})\end{array}$ & $\begin{array}{l}\text { ultimate } \\
\text { shear } \\
\text { strength } \\
(\mathrm{MPa})\end{array}$ & $\begin{array}{l}\text { shear } \\
\text { elastic } \\
\text { modulus } \\
(\mathrm{MPa})\end{array}$ & $\begin{array}{c}\text { elastic } \\
\text { modulus of } \\
\text { shear } \\
(\mathrm{MPa})\end{array}$ \\
\hline$\overline{G J Z 200 \times 300 \times 41(C R)}$ & 63 & 18.4 & 454 & 10.6 & 70 & 293 & 1.00 \\
\hline
\end{tabular}

\subsection{Thermal aging processing of test specimens}

The specimens were first put in high-temperature test chamber to reach $70^{\circ} \mathrm{C}$. The distance between the samples is greater than $20 \mathrm{~mm}$.

Table 3 Thermal aging processing of specimens

\begin{tabular}{|c|c|c|c|c|}
\hline $\begin{array}{c}\text { loading } \\
\text { modes }\end{array}$ & specimen & $\begin{array}{l}\text { days of } \\
\text { thermal } \\
\text { aging } \\
\text { processing }\end{array}$ & $\begin{array}{l}\text { Dimensions before } \\
\text { thermal aging } \\
\text { processing }(\mathrm{mm})\end{array}$ & $\begin{array}{l}\text { Dimensions } \\
\text { after thermal } \\
\text { aging } \\
\text { processing } \\
(\mathrm{mm})\end{array}$ \\
\hline \multirow{5}{*}{ Shear test } & GJZ200×300×41(CR)JYBZ01 & 0 & $200 \times 301 \times 43$ & \\
\hline & GJZ200×300×41(CR)JYRF20 & 20 & $199 \times 300 \times 41$ & $199 \times 300 \times 40$ \\
\hline & GJZ200×300×41(CR)JYRF40 & 40 & $200 \times 300 \times 41$ & $199 \times 299 \times 40$ \\
\hline & GJZ200×300×41(CR)JYRF60 & 60 & $199 \times 300 \times 42$ & $198 \times 298 \times 40$ \\
\hline & GJZ200×300×41(CR)JYRF80 & 80 & $199 \times 300 \times 42$ & $199 \times 300 \times 40$ \\
\hline
\end{tabular}

A total of 10 specimens were tested. There were $0,20,40,60$ and 80 days thermal aging processing for specimens. The dimensions of all specimens before and after thermal aging processing were measured according to the method put forward by elastomeric pad bearings for highway bridges [11].The Dimensions of specimens have no obvious change after thermal aging processing. Test specimens in detail are described in Table 3.

\subsection{Test Setup, Instrumentation and Procedure}

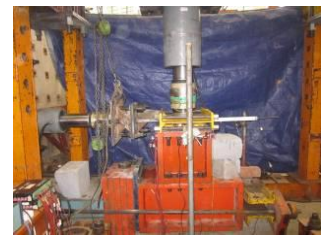

Fig.1 Photograph of shear testing setup

The shear tests were carried out in the Structural Engineering Laboratory of Shenyang Jianzhu University. The test setup was shown in Fig. 1. The shear load was applied by a $5000 \mathrm{kN}$ pressure testing machine.

\section{Experimental Results}

Fig. 2 shows failure modes of specimens in shear test. The vertical load increased gradually, specimens were in elastic state when the cracks did not appear. Loading were in a short stagnation when a few fine cracks appeared around agglutinate places of steel plates and rubber of specimens' edge. After that, the vertical displacement increased slowly, but the horizontal displacement increased sharply with load increasing. Meanwhile, protrusions appeared around specimens' edge, and the cracks got larger and deeper fast. The vertical displacement and horizontal displacement increased slowly and load declined precipitously when specimens devastated. The layer-crack damage characteristics of specimens were obvious because steel plates broke away from rubber. The specimens after thermal aging processing were more probably brittle failure than the standard specimen. Moreover, the exposure of steel plate, cracks and other failure phenomena were more serious than the standard specimen. 


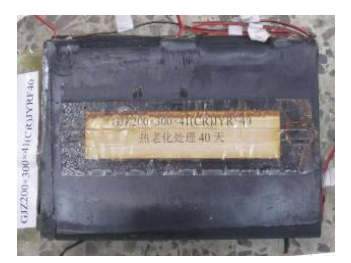

Fig. 2 Failure modes of GJZ200×300×41(CR)JYRF40 in shear tests

The mechanical properties of specimens are shown in table 4 . The shear capacity, ultimate shear strength and shear elastic modulus of the specimens decreased obviously with the increasing in time of thermal aging processing.

Table 4 the mechanical properties of specimens in shear tests

\begin{tabular}{|c|c|c|c|c|c|c|c|c|}
\hline \multirow{2}{*}{ specimen } & \multirow{2}{*}{$\begin{array}{c}\text { shear } \\
\text { capacit } \\
\mathrm{y} \\
(\mathrm{kN})\end{array}$} & \multirow{2}{*}{$\begin{array}{l}\text { ultimat } \\
\text { e shear } \\
\text { strengt } \\
\text { h } \\
(\mathrm{MPa})\end{array}$} & \multicolumn{3}{|c|}{$\begin{array}{c}\text { displacement } \\
\text { corresponding to ultimate } \\
\text { shear strength }(\mathrm{mm})\end{array}$} & \multicolumn{3}{|c|}{$\begin{array}{l}\text { displacement } \\
\text { corresponding to shear } \\
\text { force } 200 \mathrm{kN}(\mathrm{mm})\end{array}$} \\
\hline & & & $\begin{array}{c}\text { vertica } \\
1\end{array}$ & $\begin{array}{l}\text { horizontal } \\
\text { longitudin } \\
\text { al }\end{array}$ & $\begin{array}{l}\text { horizonta } \\
1 \text { lateral }\end{array}$ & $\begin{array}{c}\text { vertica } \\
1\end{array}$ & $\begin{array}{l}\text { horizontal } \\
\text { longitudin } \\
\quad \text { al }\end{array}$ & $\begin{array}{l}\text { horizonta } \\
1 \text { lateral }\end{array}$ \\
\hline $\begin{array}{c}\text { GJZ200×300×41(CR)JYBZ } \\
01\end{array}$ & 237.08 & 3.95 & 0.35 & 0.92 & 26.56 & 0.18 & 0.50 & 20.15 \\
\hline $\begin{array}{c}\text { GJZ200×300×41(CR) } \\
\text { JYRF20 }\end{array}$ & 219.10 & 3.65 & 0.27 & 0.57 & 8.87 & 0.27 & 0.57 & 7.39 \\
\hline $\begin{array}{c}\text { GJZ200 } \times 300 \times 41(\mathrm{CR}) \mathrm{JY} \\
\mathrm{RF} 40\end{array}$ & 198.08 & 3.30 & 0.29 & 0.74 & 9.43 & 0.29 & 0.75 & 9.70 \\
\hline $\begin{array}{c}\text { GJZ200×300×41(CR) JY } \\
\text { RF60 }\end{array}$ & 186.88 & 3.11 & 0.33 & 0.81 & 8.88 & 0.34 & 0.85 & 10.13 \\
\hline $\begin{array}{c}\text { GJZ200×300×41(CR) JY } \\
\text { RF80 }\end{array}$ & 177.73 & 2.96 & 0.31 & 0.48 & 7.71 & 0.35 & 0.86 & 10.00 \\
\hline
\end{tabular}

\section{Test analysis}

The average summer temperature in most parts of the world is $20 \sim 30^{\circ} \mathrm{C}$. Therefore, the average summer temperature is taken as $25^{\circ} \mathrm{C}$. Many tests of rubber bearings on Tomei Expressway which made by Japan Highway Public Corporation showed that those ultimate tensile strength, extension rate and shear modulus after thermal aging processing $\left(60 \sim 80^{\circ} \mathrm{C}\right)$ of $1,200 \sim 2,040$ hours would be the equivalent of 100 -year thermal aging state at $23^{\circ} \mathrm{C}[12]$. Moreover, some tests showed that rubber would be at twice speed of thermal aging when temperature was increased $10^{\circ} \mathrm{C}$. The thermal aging processing of $20,40,60$ and 80 days at $70^{\circ} \mathrm{C}$ is the equivalent of thermal aging $15,30,45$ and 60 years in natural environment.

The test results show that the attenuation trend of ultimate shear strength accords with power function. The attenuation model is acquired by regressing data of experiment with the least square method. Fig. 3 shows the attenuation curve of ultimate shear strength of laminated neoprene bridge bearing pads. The attenuation function is shown as follows

$$
Z=5.4848 x^{-0.1499}
$$

Where, $Z$ is ultimate shear strength; $\mathrm{x}$ is years of thermal aging.

\subsection{Influence on shear elastic modulus}

The measured shear elastic modulus of laminated neoprene bridge bearing pads is summarized in Table 5. The measured shear elastic modulus of standard specimen is $292.42 \mathrm{MPa}$ which is identical to the stipulated index of shear elastic modulus (293 MPa). However, shear elastic modulus of laminated neoprene bridge bearing pads decreases significantly with the increasing in aging time. 
Table 5 Measured shear elastic modulus of laminated neoprene bridge bearing pads

\begin{tabular}{cc}
\hline Specimen & $\begin{array}{c}\text { Measured shear elastic } \\
\text { modulus }(\mathrm{MPa})\end{array}$ \\
\hline GJZ200×300×41(CR)ZYBZ01 & 292.42 \\
GJZ200×300×41(CR)ZYRF20 & 191.52 \\
GJZ200×300×41(CR)ZYRF40 & 172.34 \\
GJZ200×300×41(CR)ZYRF60 & 152.66 \\
GJZ200×300×41(CR)ZYRF80 & 140.41 \\
\hline
\end{tabular}

The test results show that the attenuation trend of shear modulus accords with power function. The attenuation model is acquired by regressing data of experiment with the least square method. The attenuation function is shown as follows

Where, $\mathrm{E}$ is shear elastic modulus.

$$
G_{1}=1.9128 x^{-0.2045}
$$

To examine and assess attenuation model and to make statistic analysis with the data by induced into attenuation function, $E$ is $194.72,166.81,152.38$ and 142.90 when $x$ is $15,30,45$ and 60 , respectively. The average ratio of calculating data to testing data is 1 , and its standard deviation and coefficient of variation are both 0.02 . The attenuation model of shear elastic modulus conform to reality well which shows that this model is applicable and has vast prospect in assessing the performance of laminated neoprene bridge bearing pads under thermal aging condition.

\section{Conclusion}

The following conclusions can be drawn within the limitations of the current tests:

(1) The shear test results show that the specimens after thermal aging processing prone to more brittle failure than the standard specimen. Moreover, the steel plate exposed, cracks and other damage phenomena are more serious than the standard specimen.

(2) With the increasing in the aging time and the deepening of the degree of thermal aging processing, shear capacity, ultimate shear strength, shear elastic modulus of the laminated neoprene bridge bearing pads decreased dramatically.

(3) The thermal aging processing has certain effect on vertical stiffness; the thermal aging processing has a greater effect on horizontal equivalent stiffness than vertical stiffness.

\section{Acknowledgments}

This research was supported by Liaoning Provincial Natural Science Foundation (201602634), Chinese Department of Ministry of Housing and Urban-Rural Development (2016-R2-039)

\section{References}

[1] Doug Wingard(2010). Use of DSC and DMA to study crystallization as a possible cause for a glove tear. Journal of Thermal Analysis and Calorimetry,102(2): 469-476

[2] E Muhammad Abdul Jamal, P A Joy and Philip Kurian(2010). On the magnetic, mechanical and rheological properties of rubber-nickel nanocomposites. Polymer Bulletin, 64(9): 907-923

[3] Hsien-Tang Chiu, Peir-An Tsai and Tzu-Chi Cheng (2006). Study of rheological behavior and miscibility of epoxidized natural rubber modified neoprene.Journal of Materials Engineering and Performance,15(1): 81-87

[4] Xie Suizhi, Liu Dengfeng, Zhou Mingluan(1989). Rubber Industry Manual (Volume I). Beijing: Chemical Industry Press, (in Chinese)

[5] Xu Donghua, Wu Huafeng, Wang Jianfen(2010). The affect of the environmental temperature on the neoprene rubber bearings the shear properties [J]. Highway. 1:76-78 (in Chinese).

[6] Kalpakidis IV, Constantinou MC(2009). Effects of heating on the behavior of lead-rubber bearings. 1: theory [J]. Journal of Structural Engineering . 135(11):1440-1449.

[7] Kalpakidis IV, Constantinou MC(2009). Effects of heating on the behavior of lead-rubber bearings. 2: verification of theory[J]. Journal of Structural Engineering. 135(11):1450-1461 
[8] DU Yong-feng, Kou Jia-liang, Kou Wei-wei(2010). Analysis of thermal mechanical of lam inated rubber bearing under high temperature[J]. Sichuan Building Science. 6(36):150-153. (in Chinese)

[9] Cheng Guisheng(2010). The forecast of the aging characteristics of natural bearings in bridge [J]. World bridges. 40(2):63-65. (in Chinese)

[10]The industrial standard of communications in the People's Republic of China. Series of elastomeric pad bearings for highway bridges (JT/T 663-2006), 2006(in Chinese)

[11]The industrial standard of communications in the People's Republic of China. elastomeric pad bearings for highway bridges(JT/T4-2004),2004(in Chinese)

[12]Zhou Minghua(2004). Service life and application measures of rubber bearings for highway bridges [J]. World bridges. 2:71-74(in Chinese) 